\title{
Developmental Sequences for the Vertical Cradle in Lacrosse: An Exploratory Study
}

\author{
Kate R. Barrett, Kathleen Williams, Jill McLester, \\ and Sara Ljungkvist \\ University of North Carolina at Greensboro
}

\begin{abstract}
Developmental sequences for the vertical cradle were hypothesized and tested using a prelongitudinal screening technique to determine comprehensiveness and developmental accuracy. Fifty-one 10- to 13-year-old children were videotaped as they ran and cradled over a flat surface. A total of 150 trials were categorized for seven components: basic rhythm, hand and arm action, stick position, top hand grip, stick head and top arm action, position of hands, and bottom arm and hand action. Lack of developmental variability occurred for the basic rhythm, hand and arm action, and hand position components. For the stick position component, more younger children were classified at the highest level than older children. The developmental sequence for the stick head and top arm component was comprehensive and age related. The role various constraints play in hypothesizing sequences of sport specific skills needs to be considered along with the quality and amount of instruction.
\end{abstract}

A major theme running through this study is the concept of developmental sequences and the role these sequences play in teaching motor skills in physical education. Specifically, the study focuses on hypothesizing developmental sequences for the vertical cradle, a skill specific to lacrosse. This skill was selected because many consider it central to and the basis of all lacrosse movement (Boyd, 1969; Green \& Kurtz, 1989; Hanna, 1980; Lewis, n.d.). In other words, the vertical cradle is "fundamental" to playing the sport-a sport-specific, fundamental skill.

\section{Theoretical Base}

Developmental sequences for fundamental motor skills (e.g., running, skipping, overarm throwing, catching) have long been accepted as an important dimension of the knowledge base of physical education teachers in Grades $\mathrm{K}-5$. Fundamental skills have always been considered general movement patterns with their adaptation and further refinement leading to specific skills of sport and dance (Wickstrom, 1983). Developmental sequences are descriptions of the series of

Kate R. Barrett, Kathleen Williams, Jill McLester, and Sara Ljungkvist are with the Department of Sport and Exercise Science at the University of North Carolina at Greensboro, 270 HHP Building, Greensboro, NC 27412. 
changes in motor skills (i.e., developmental levels or steps) from their initial attempts to their most advanced performance. They focus on qualitative change and are related to, but not determined by, age (National Association for Sport and Physical Education [NASPE], 1995; Roberton, Williams, \& Langendorfer, 1980). Currently, we use two approaches to identify sequences for use in research and practical settings, one developed by Roberton (1982) and the other by Seefeldt and Haubenstricker (1982). Roberton's (1982) model focused on individual components of the body because she discovered in her research that "development in the different components occurred at different rates within the same child" (p. 297). Her approach identified steps or levels for each component. For example, in developmental sequences for hopping, Halverson and Williams (1985) identified four steps for the leg action and five for the arm action. Validation studies like these make it clear that "the movement components did not develop in the parallel, lockstep fashion that is suggested by the total body configuration stages" (Roberton, 1982, p. 297).

Seefeldt and Haubenstricker's (1982) model described the total body configuration during the performance of a skill and then identified it as a stage (e.g., Stage 1, Stage 2). They agreed with Roberton (1982) that "all of the patterns or subroutines within a stage (as defined by us) do not advance as an indivisible unit" (Seefeldt \& Haubenstricker, 1982, p. 313). They also believed that they "found sufficient cohesion between certain of these subroutines so that listing them within a 'stage' appeals to us as the least complicated way to describe a particular developmental task" (p. 313). Seefeldt and Haubenstricker found this approach useful when working with practicing teachers.

Since the late 1970s, textbooks written for children's physical education have included developmental sequences for selected fundamental motor skills (Graham, Holt/Hale, \& Parker, 1993; Logsdon et al., 1977) or, if not sequences per se, an analysis of what the authors thought to be the most mature pattern. This latter approach has been a part of the literature since the early 1920s (Wild \& White, 1924) and is still being used (Nichols, 1994). With the current emphasis on the design of developmentally appropriate physical education activities, the concept of developmental sequences has much to offer in the way of guiding teachers philosophically as well as providing them a way to assess progress and revise tasks informed by developmental information. A major role of developmental sequences is to

help teachers know if their interventions are working in a positive or negative fashion; for instance, seeing whether a child's movement is progressing or regressing would be the key to knowing when a child was ready for further complexity or was needing simplification within a particular task. Also, teachers can use developmental sequences as formal or informal assessment instruments. (Roberton, 1989, p. 375)

Although the concept of developmental sequences is not new, its application to research and practice has been almost entirely linked to fundamental motor skills, and thus used primarily by teachers of young children. Two exceptions are noted. The first is the work done by Wickstrom (1983) in which he suggested connections between the movement patterns of selected fundamental motor skills and movement patterns of selected sport skills. The second is Messick's (1991) hypothesized and partially validated developmental sequences for the overhand tennis serve. 
Wickstrom (1983) defined fundamental (or basic) motor skills as "common motor activities with specific patterns" (p. 7). He saw them as "general skills that form the bases for the more advanced and more specific motor activities, such as sport skills" (p. 7). Sport skills he defined as "advanced versions of basic skills that are used in particular ways" (p. 9). Wickstrom highlighted several specific connections similar to Broer's (1973) view of the relationship between fundamental and specific sport skills through their use of mechanics. For example, he related catching as a fundamental skill to catching a football and sidearm striking to baseball batting and the forehand stroke in tennis. His basic skills were general patterns to be accommodated to the context of the sport itself. Because the skill chosen for this project was unrelated to a basic or fundamental skill, we began to speculate that there was an important type of skill (in sport) between Wickstrom's basic skill and sport skill, one that was specific to the sport, but at the same time fundamental or basic to that sport.

Messick (1991), using the component approach to developmental sequences as proposed by Roberton (1982), hypothesized sequences for the overhand tennis serve for two components in the preparation phase (i.e., preparatory backswing and trunk actions) and four for the force production phase (i.e., elbow, forearm/ racket, trunk, and feet/leg actions). To our knowledge, this is the only formal study focused on a skill specific to a sport and not a fundamental motor skill. Of her hypothesized sequences, those for the preparatory trunk, elbow, and forearm/racket actions met the prelongitudinal screening criteria proposed by Roberton (1978) and were considered ready for validation through longitudinal study. Sequences for the other component actions (preparatory backswing, trunk for force, and feet/ legs), did not meet the screening criteria and needed further study.

Knowledge of developmental sequences represents a unique way of understanding movement for teaching physical education. It represents a special form of teacher knowledge that Shulman (1986) identified as pedagogical content knowledge. He described it as a form of knowledge that integrated content knowledge (in our case, knowledge of the movement in the motor skill) with pedagogy (in our case, how that movement skill might be taught and learned). Pedagogical content knowledge is often defined broadly to include aspects of teacher knowledge such as instructional strategies, purposes for teaching, curriculum and students' understanding of the material, to mention a few (Grossman, 1990). In this study, however, it will be narrowly defined to reflect knowledge about how a particular movement develops over time; that is, the process children might go through to learn a skill from their initial attempts to their most advanced performance (i.e., actual motor patterns described and arranged in a developmental sequence). This definition relates specifically to that aspect of pedagogical content knowledge that Grossman identified as students' understanding of the material (i.e., what they have learned and how they have come to learn it).

What makes knowledge of developmental sequences so important to physical education teachers is that developmental sequences allow teachers to see the movement performance of their children along a "continuum of correctness" so that progress can be indicated even if the movement does not look like the most mature model (M.A. Roberton, personal communication, July 1994). In other words, the sequences are tools for observation, assessment, and interpretation about developmental progress. For teachers who teach from a developmental perspective, this model of motor development credits the movers for what they are able to do 
and recognizes that the movement is "right," given the performer-task constraints at that time (M.A. Roberton, personal communication, July 1994). This model is in contrast to the more familiar error detection model (Schmidt, 1991), which focuses on what the movers cannot do; the movements are perceived by children and teachers alike as "wrong."

But a major problem exists. At this time in our history, we do not have a lot of validated sequences to inform our instruction, and thus, as researchers and teachers, we must start hypothesizing our own. Our study addresses this need by placing hypothesizing developmental sequences for a skill specific to a sport as central to its purpose. Earlier, we pointed out that most hypothesized sequences, except for the work of Messick (1991), are of fundamental motor skills performed in a single, controlled setting. Besides the need to know more about the process of hypothesizing developmental sequences itself, we need to find out what issues exist that might be unique to hypothesizing developmental sequences for skills related to specific sports (e.g., forearm pass in volleyball, field hockey dribble) in contrast to fundamental skills. This type of inquiry has to occur if the concept of developmental sequences is to become more useful for practicing specialists and researchers.

Thus, the purpose of this study was twofold: (a) to hypothesize developmental sequences for the vertical cradle in lacrosse, and (b) to determine their comprehensiveness and developmental accuracy.

\section{Procedures}

\section{The Vertical Cradle}

As previously mentioned, the vertical cradle was selected for study because it is a skill specific to a sport and is considered the basis of all lacrosse skills (i.e., a skill "fundamental" to playing the sport). We could study this skill because of the existence of a lacrosse stick modified specifically for children (i.e., the STXBALL stick). This stick gives children the opportunity to perform a skill which otherwise would have been too difficult for them had they used the adult stick. The STXBALL stick is lighter (i.e., plastic) and slightly shorter than sticks made for adults. It has a deep pocket made of plastic webbing with a "keeper strap" placed across the front of the pocket to help keep the ball in. Additionally, the first author has had extensive experience working with the vertical cradle across all skill levels from beginners to advanced players and was part of a coaching group when "the easy way" to teach cradling was first introduced into the literature approximately 30 years ago (Lewis, n.d., p. 9). At that time, this approach was described in as follows:

A quick way to get players to feel the cradling rhythm is to ask them to put their sticks down, clasp their hands together in front of them and run. Once they have felt how the arms swing naturally, they can pick up their stick with the correct grip; hold it with their hands together in the middle of the handle and run. When the stick is moving easily simply move the hands apart keeping the rhythmic action going. The hands should finish with one at the collar and the other at the bottom of the handle. (p. 9)

This description of a way to introduce cradling to a beginning lacrosse player is a good example of Shulman's (1986) concept of pedagogical content knowledge. The tasks above integrate knowledge of movement (i.e., content specific to 
lacrosse) with how to elicit a desired pattern (i.e., pedagogy specific to lacrosse movement).

\section{Developmental Sequences}

The developmental sequences used in this study were first hypothesized by Barrett and Collie (1996) and further refined as part of this study. Guided by the procedures suggested by Roberton et al. (1980), we used three basic steps: (a) identify components of the vertical cradle, (b) generate a list of all the different movement patterns we had seen or knew to occur within each component, and (c) hypothesize the sequences of changes from primitive to advanced or from least efficient to most efficient. We did not follow these steps linearly; rather, we moved between and among them. This approach is similar to the qualitative research techniques of inductive analysis (Patton, 1990) and constant comparison (Glaser \& Strauss, 1967). Use of these steps was supported by relevant literature, extensive data gathered from observation (live, video, photographs) of children and adults cradling and learning to cradle using the STXBALL stick, observation (live, video, and photographs) of adults playing competitive lacrosse, and personal lacrosse teaching and playing experience of the first author.

Based on the above procedures, seven components were identified (described for players using their right hand at the top of the stick):

\section{Component 1: Basic rhythm}

- Step 1: Nonopposition. Stick and arms move in opposition to running action (i.e., upper body and legs move in non-opposition of each other).

- Step 2: Opposition. Stick and arms move in concert with running action (i.e., upper body and legs move in opposition to each other).

Component 2: Hand and arm action

- Step 1: Opposition. Hand and arms work in opposition to each other (i.e., see-saw).

- Step 2: Together. Hands and arms work together.

Component 3: Stick position

- Step 1: Horizontal. The stick is carried horizontal or slightly angled to the floor.

- Step 2: Diagonal. The stick is carried at a $45^{\circ}$ angle to the floor, with the stick head forward of the body.

- Step 3: Vertical. The stick is carried at a $90^{\circ}$ angle to the floor, with the stick head slightly forward of the body.

Component 4: Top hand grip (described in relation to pocket facing player)

- Step 1: No wrist pronation. The palm is placed behind the stick (facing the body).

- Step 2: Partial wrist pronation. The palm is placed beside the stick (facing left).

- Step 3: Full wrist pronation. The V (joint between the thumb and first finger) is placed in line with or slightly to the side of the pocket.

Component 5: Stick head and top arm action

- Step 1: Little/no action. The stick head is stationary or may move slightly as a result of little or no shoulder or wrist action.

- Step 2: Partial cradle. The stick head wraps partially around the ball as a result of limited shoulder adduction followed by abduction and limited wrist supination followed by pronation. 
- Step 3: Full cradle. The stick head smoothly wraps around the ball as a result of full shoulder adduction followed by abduction and full wrist supination followed by pronation.

Component 6: Position of hands

- Step 1: One hand. One hand (top or bottom) remains on the stick.

- Step 2: Two hands close together. Both hands remain close together on any part of the stick.

- Step 3: Two hands slightly apart. Both hands remain approximately 1 foot apart on the stick with the top hand near the top of stick and the bottom hand on the lower half of the stick.

- Step 4: Two hands apart. Both hands remain about shoulder width apart or further on the stick with the top hand placed within the top third of the stick and the bottom hand within the bottom half.

Component 7: Bottom arm and hand action

- Step 1: Elbow extended, hand below waist. The elbow is partially to fully extended with the hand and forearm below the waist. No wrist, elbow, or shoulder action occurs so the bottom hand and arm remain still. (The top arm and hand are doing all the work.)

- Step 2: Elbow extended, wrist extension/flexion. The elbow is partially to fully extended with the hand and forearm below the waist. Slight wrist extension followed by flexion is evident. No action occurs in the elbow and shoulder.

- Step 3: Elbow extends/flexes. The elbow extends when cradling to the left side dropping the bottom hand below the waist; the elbow flexes when cradling to the right side bringing the bottom hand even with the waist. Limited or no extension and flexion of the wrist occurs.

- Step 4: Elbow flexed, pumping action. The elbow remains relatively fixed in a flexed position with the hand and forearm parallel to the floor as the elbow pumps back and forth as a result of shoulder hyper-extension followed by flexion. There is limited or no wrist extension followed by flexion.

- Step 5: Elbow flexed, shoulder rotation. The elbow remains next to the hip in a flexed position as the hand and forearm move from side to side remaining parallel to the floor as a result of full shoulder external rotation followed by internal rotation and full wrist extension followed by flexion.

\section{Participants}

Fifty-one children from two intact classrooms, ranging in age from 10 to 13 years, participated in this study. Twenty-six children were in the 10- to 11-yearold-group and 25 were in the 11- to 13-year-old-group. The younger children came from an elementary school in Burlington, North Carolina, and the older children from a middle school in Rockville, Maryland. These participants were selected because of their availability and the age span they represented. Because the vertical cradle was a sport skill and not a fundamental skill, we wanted to be sure that our participants had had some experience with STXBALL and the STXBALL stick. The age span was judged to be large enough to include participants with developmental levels ranging from the least to the most advanced. Pilot work with children below the third grade demonstrated that the STXBALL stick used in this study was too large and heavy for them; they could not handle it with any consistency. 
At the time of the data collection, the 10- to 11-year-olds had received four 45-minute lessons in lacrosse, and the 11- to 13-year-olds received six 30-minute lessons. None of the children had had any experience playing lacrosse before this time, although the children from Maryland would have had more opportunities to observe it either on television or as a spectator at an athletic event than would the children from North Carolina. Parents or guardians read and signed informed consent forms prior to the children's participation.

Both teachers of these classes, Kelly and Chris (pseudonyms), were certified physical education specialists. Kelly, a female who was the younger children's teacher, had taught for 16 years, and Chris, a male who was the middle school teacher, had taught for 8 years. This was Kelly's second time teaching lacrosse and Chris's first. In addition, Kelly had attended a full-day workshop in 1994 specifically focused on helping teachers unfamiliar with lacrosse teach the modified version (i.e., STXBALL) to elementary-aged children.

\section{Data Collection and Reduction}

All children were videotaped as they ran and cradled over a flat surface, pavement for the younger children and grass for the older ones. Their instructions were to run as quickly as they could straight toward the camera while cradling the ball. If they dropped the ball during the trial, they immediately repeated it. The children were filmed in groups ranging in size from 3 to 7 , with all children in each group completing one trial before they took the next. Each child took three trials. The range in group size was due to scheduling problems and absences. The children all used the STXBALL stick and a plastic ball designed for use with it. They were given the option to use the $91.44 \mathrm{~cm}$ stick they were currently using in their classes or to use one of a shorter length (i.e., $81.28,83.82$, or $86.38 \mathrm{~cm}$ ). Of the 26 children in the 10 - to 11 -year-old group, 19 used the $91.44 \mathrm{~cm}$ stick, 2 the $83.82 \mathrm{~cm}$ stick, and 2 the $86.36 \mathrm{~cm}$ stick. In the older group, 13 used the $91.44 \mathrm{~cm}$ stick, 7 the $86.36 \mathrm{~cm}$ stick, and 5 the $81.28 \mathrm{~cm}$ stick. All children were given the option of two practice trials. The camera was placed $73.15 \mathrm{~m}$ from the children's starting point, which gave them a full $54.86 \mathrm{~m}$ to run before they had to turn away from the camera, clearing the path for the next runner. Markers where placed approximately $1.22 \mathrm{~m}$ apart at $4.57 \mathrm{~m}$ intervals indicating the path and direction the children were to take.

Two different cameras were used to collect the data. A JVC model KY17 (VHS) video camera was used to film the younger children with the aperture set at $\mathrm{f} / 16$, the focal length at $30 \mathrm{~mm}$, and the shutter speed at 1/250 of a second. A Canon model L-1 (Hi 8) video camera was used to film the older children, with the aperture set between $\mathrm{f} / 5.6$ and $\mathrm{f} / 4$, the focal length at $100 \mathrm{~mm}$, and the shutter speed also at $1 / 250$ of a second. Before data reduction, these data were transferred to VHS.

\section{Reliability of Categories}

Two judges were trained to categorize trials of the vertical cradle using the developmental sequences hypothesized for this skill. Training included four 2hour sessions, at which time both judges worked with the first author to learn how to categorize each step within each component. In addition, ground rules to assist in objectivity and reliability were established during these sessions. 
The judges categorized trials for each child for all components except Component 4 (top hand grip). Component 4 was eliminated during judges' training sessions as it became clear that even with the variable playback capabilities of the Sony VCR SLV-400 videodeck, detailed observation of the top hand was not possible. It was only at the end of the trial, when the children were closest to the camera, that their hand could be seen clearly enough to categorize it. Before reducing the data, a subset of 10 randomly selected trials was selected from the data and categorized independently by each judge. A criterion of $85 \%$ exact agreement indicated acceptable objectivity (Roberton, 1977).

Interobserver objectivity was acceptable for Component 1 (85\%), Component $2(100 \%)$, Component $3(87 \%)$, and Component $6(100 \%)$. Objectivity was not acceptable for Components 5 or 7 (75\% for both). Observer disagreement for Component 5 (top hand and arm action) appeared to occur because the amount of the actual "wrap around the ball" was difficult to judge, not because other movement patterns were evident and could not be categorized. Thus, we refined the decision rule for observing and categorizing this component to make it easier to judge the differences between the three steps. When at least one side of the stick head and part of the other side were visible during the trial, we defined this as Step 2 (partial cradle). If both sides of the stick head were visible first on one side and then the other throughout the majority of the trial, we defined this as Step 3 (full cradle). The side of the stick head is that part of the stick that is visible when the pocket is facing directly to the right or left when viewed in relation to the individual cradling.

Disagreement between judges for Component 7 (bottom arm and hand action) occurred in two places. First, they had difficulty distinguishing between Steps 1 and 2 and between Steps 3 and 4 . In Steps 1 and 2, the main difference between the movement patterns was in the wrist action: none in Step 1 and slight flexion/ extension in Step 2. The judges were unable to distinguish this subtle difference. For the purposes of this study, we decided to collapse these two steps into one, resulting in Component 7 having four steps instead of five. Second, Step 3 was rewritten (now Step 2 below) to reflect the observation by the judges that when the elbow extended it did not always drop below the waist on the left side; it occasionally dropped below on the right. Finally, whenever the arm and hand position were described in relation to the waist, it was worded to make clear whether the arm and hand were below, even with or above waist level. The following presents the revised steps for this component:

Component 7: Bottom arm and hand action

- Step 1: Elbow extended, hand below waist. The elbow is partially to fully extended with the hand below the waist. Throughout the cradle, the hand remains below the waist.

- Step 2: Elbow extends/flexes. The elbow extends when cradling, dropping the bottom hand below the waist. The elbow flexes, bringing the bottom hand even with or above the waist. Limited or no wrist or shoulder action occurs.

- Step 3: Elbow flexed, pumping action. The elbow remains relatively fixed in a flexed position with the hand even with or above the waist. The elbow "pumps" back and forth as a result of shoulder hyperextension, followed by flexion (elbow is thrust backward). There is limited or no wrist extension followed by flexion. 
- Step 4: Elbow flexed, shoulder rotation. The elbow remains next to the hip in a flexed position. The hand and forearm move from side to side ("opening and closing"), staying even with or above the waist as a result of external rotation of the shoulder, followed by internal rotation and extension of the wrist, followed by flexion.

Following these revisions in the components, we reduced the data in four phases and calculated the percentage of exact agreement between the two judges at the completion of each phase. If necessary, the decision rules were reviewed. The four phases included: (a) older children, Participants 1-12, 35 trials (1 discarded); (b) older children, Participants 13-25, 37 trials (2 discarded); (c) younger children, Participants 26-41, 48 trials; and (d) younger children, Participants 4251,30 trials. All of the discarded trials were those in which the child ran out of camera view. Percentages of exact agreement for all components across all trials were $85 \%$, except for Component 7 in Phase 1 (74\%) and Phase $2(81 \%)$. Disagreements between judges for Component 7 were attributed primarily to the type of clothing worn by some of the children and not the descriptions of movement patterns. (Much of the clothing was loose, long and big and thus often obscured their waists or action at the elbow.) Intrajudge estimates of objectivity were obtained by recategorizing 37 trials one week later for Participants 26-37 (36 trials). These estimates were all above the $85 \%$ criterion of exact agreement for all components.

\section{Data Analysis}

A total of 153 trials were collected, 150 of which were used in the analysis. These included 78 for the younger children and 72 for the older children ( 3 had to be eliminated). Graphs for each component were made by plotting the frequency of occurrence for each step for the 10- to 11-year-olds and for the 11- to 13-yearolds. In turn, these graphs were examined for their comprehensiveness and developmental accuracy (Halverson \& Williams, 1985; Roberton et al., 1980; Stroymeyer, Williams, \& Schaub-George, 1991). The criterion of comprehensiveness is met when the developmental steps hypothesized for each component describe all the movement patterns observed. In other words, all the movements observed can be categorized (Halverson \& Williams, 1985). Two questions guide the assessment of developmental accuracy: "Are the sequence steps in the same relationship to each other as hypothesized?" (i.e., sequence order) and "Are each of the sequence steps rising or declining in frequency as hypothesized?" (i.e., sign of the functions) (Roberton et al., 1980, p. 728).

\section{Results and Discussion}

\section{Component 1: Basic Rhythm}

For the basic rhythm component, $92 \%$ of all trials for both age groups were categorized at Step 2, and $8 \%$ of the trials for the 12-year-old group were categorized at Step 1. Eight percent of the trials could not be categorized for children in the 10-year-old group (see Figure 1). The high frequency of occurrence for Step 2 was not surprising as the oppositional rhythm is closely linked to the fundamental 

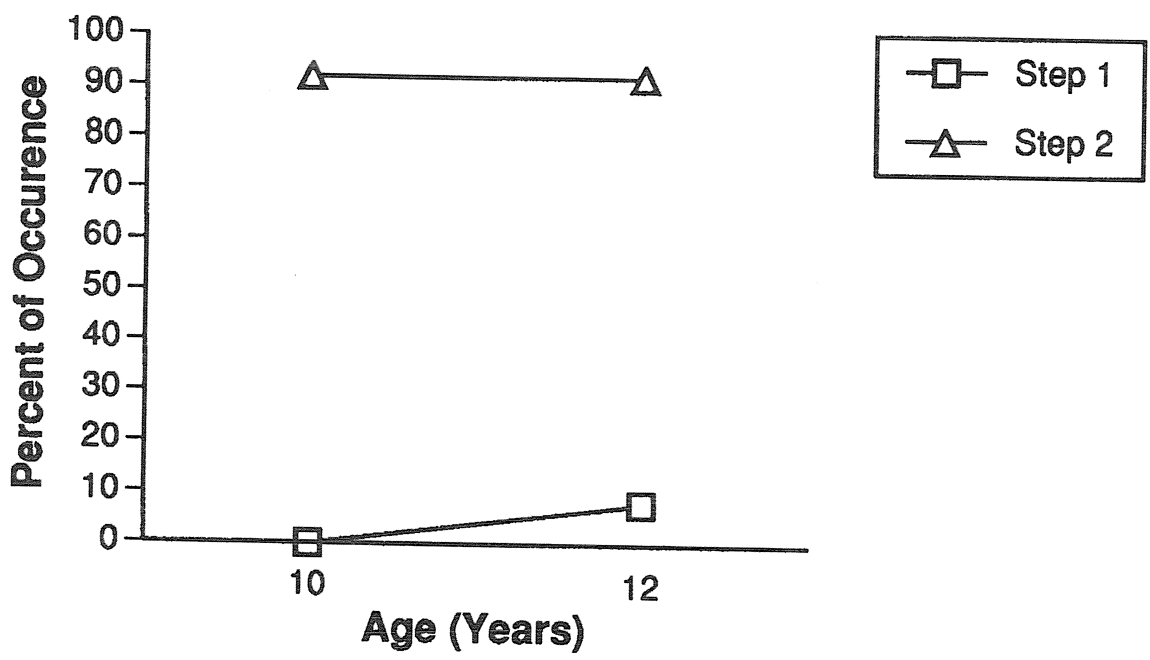

Figure 1 - Basic rhythm component percentages of occurrence. Eight percent of the trials could not be categorized for the 10 -year-old children.

motor skill of running, a skill the children could already perform. In running, the arms and legs work in opposition, with the right arm and left leg moving forward together followed by the left arm and right leg. The arm action that accompanies the leg action is an opposite reaction to the rotary action of the hips, this latter action being the result of the leg action (Hay, 1985). When learning to cradle, if the stick can be held in a vertical or slightly diagonal position while running, and if the running action is fast enough, the oppositional pattern hypothesized as Step 2 will usually emerge. The relationship between the stick position and running pattern indicates that a basic coordinated movement pattern exists between the upper and lower body that has been transferred to the stick, a pattern that will have to be maintained and strengthened if it is to act as the main support for the development of the other components. Although the vast majority of children in each of the two groups demonstrated the oppositional rhythm in the basic cradling, the size of their swinging action varied considerably from just being noticeable to swinging clearly from one side of their body to the other.

In those trials in which the movement patterns observed could not be categorized, the children held their sticks, stationary, in front of their bodies as they ran the distance for each trial. Except for limited compensatory action needed to keep their balance, the sticks of these children appeared to remain fixed in a place directly in front of them. In our pilot work on teaching children to cradle, this movement pattern was observed. Because it was seen, however, for such a short time period, we did not think it was part of the sequence. That it also appeared in two of the children in the younger group of this study suggests that we may have to reconsider this decision.

\section{Component 2: Hand and Arm Action}

The same pattern of results that emerged for Component 1 was also evident for Component 2 (see Figure 2). A majority of all trials, $92 \%$ for the 10 -year-olds 


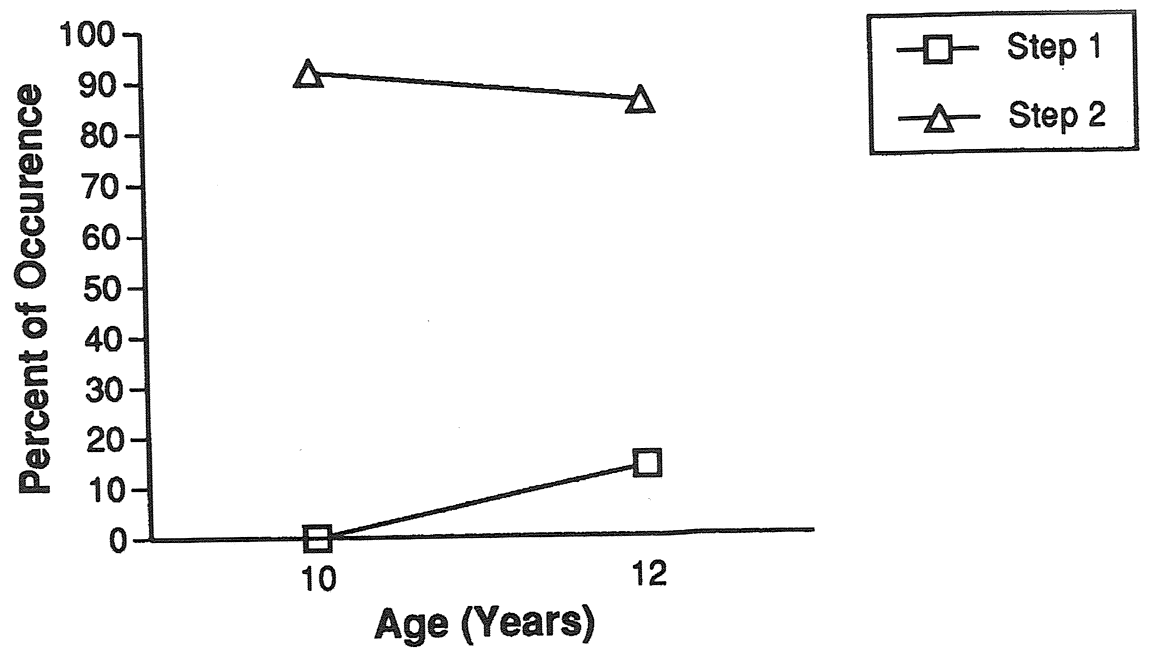

Figure 2 - Hand and arm action component percentages of occurrence. Eight percent of the trials could not be categorized for the 10 -year-old children.

and $86 \%$ for the 12 -year-olds, was categorized at the most advanced level for this component (Step 2: Together). This demonstrated that when most of the children ran and cradled, their arms and hands moved together and in the same direction. These results were expected since the majority of children in both groups were classified at the most advanced level of the basic rhythm component (Step 2: Opposition) and held their stick vertically or slightly diagonal (see data for Component 3: Stick Position). When the stick remains vertical or slightly diagonal throughout the cradle, and the swinging of the stick (i.e., the cradling action) coincides with the opposition of the legs and arms in the running action, the hands and arms will usually move together. Although the majority of children were able to swing their top and bottom arms and hands together and in the same direction, variation was observed in the distance through which their arms and hands moved. For instance, some children's bottom arms and hands moved through less space than did their top arms and hands, whereas other children's arms and hands did the reverse.

As in the data set for Component $1,8 \%$ of the trials for the younger children could not be classified. These data were from the same two children whose trials could not be classified in Component 1 . Since they held their sticks motionless while cradling, this result was expected. For the children in the 12-year-old group that were classified in Step 1, their arms and hands moved in opposition to each other; that is, their top arms and hands went in one direction while their bottom arms and hands went in another.

\section{Component 3: Stick Position}

Whereas in Components 1 and 2 the vast majority of trials were classified at the most advanced level for both groups, this was not true for Component 3 (see Figure 3 ). For the 10-year-old group, children were observed to hold the stick diagonally 


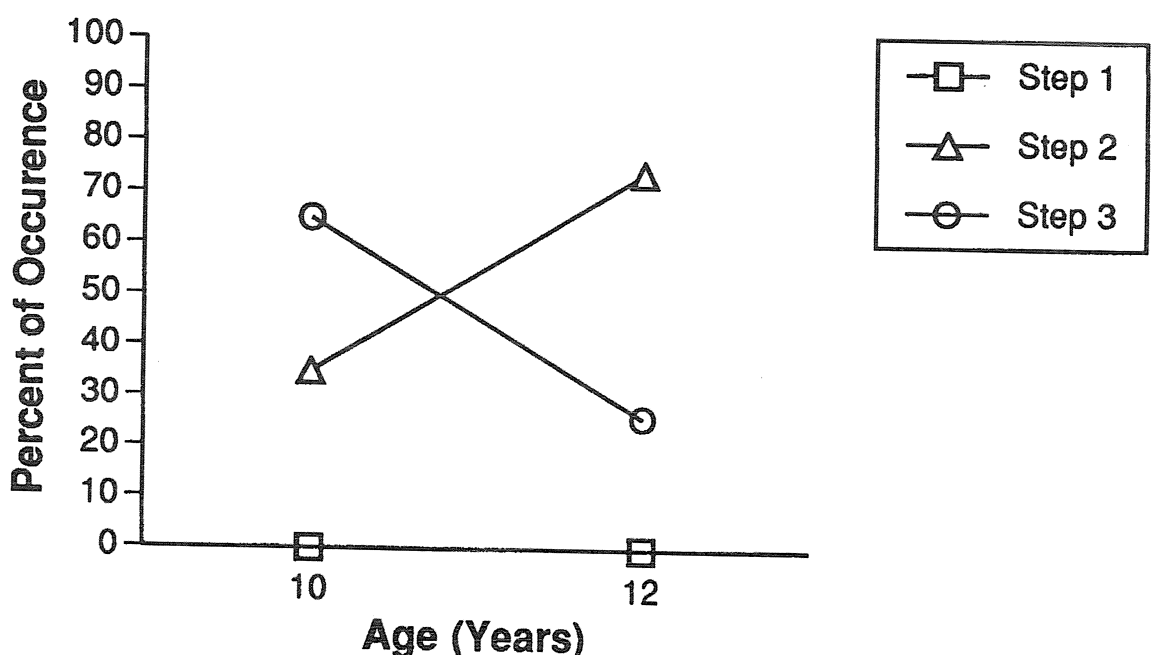

Figure 3 - Stick position component percentages of occurrence.

(Step 2) in 35\% of all trials classified and vertically (Step 3) in $65 \%$ of all trials classified. This pattern of results, however, was reversed for the 12 -year-olds. In $74 \%$ of all trials classified, the older children held their sticks diagonally (Step 2), and in $25 \%$ of all trials, they held them vertically (Step 3). In other words, more of the younger children were performing at the most advanced developmental level than were the older children, just the reverse of what you might expect (Roberton et al., 1980). None of the children in either group, during any trial, held their stick horizontally (Step 1).

The younger children's higher occurrence at Step 3 was attributed to the different lacrosse background of the two teachers in this study. Their teacher had participated in a full-day workshop designed specifically for teachers with no lacrosse background. The workshop focused on how to teach lacrosse skills and tactics to young children using the modified stick. One of the concepts that was continuously stressed throughout this workshop was the importance of holding the stick vertical throughout the cradle, especially when first learning to perform it. The teacher of the older group had not had this experience.

The absence of any children holding their stick horizontally was not totally unexpected since this specific stick position had been observed primarily when children were first learning to catch a tossed ball and then cradle. In children's initial attempts to catch a tossed ball, they often bring their bottom hand up parallel with their top hand in an effort to keep the ball in the stick; thus, they end up holding their stick in a horizontal position. Since the stick is in this position, they tend to keep it this way as they try to cradle following the catch, especially in the early stages of learning. The fact that no child demonstrated this pattern in this study suggests this step may not be part of the development of the vertical cradle, when it is performed as a single skill and not in combination with others (e.g., after catching or picking up a loose ball). Further study is needed to answer this question. What could be considered, however, is breaking the current Step 2 into two separate levels, one that included a stick position just off the vertical to $45^{\circ}$ and 
another greater than $45^{\circ}$. This difference in stick position is easily observed on the video tapes.

\section{Component 4: Top Hand Grip}

For this study, Component 4 was not formally observed and categorized as it was too difficult to see clearly on the video tapes. Although we could not see it directly, being able to classify it in future studies is essential since other components are directly related to it, particularly Components 5. As part of the cradling action, the top hand grip is considered one of the most critical features of the skill (Boyd, 1969; Green \& Kurtz, 1989; Hanna 1980). For example, when children can place their top hand so the $\mathrm{V}$ of the thumb and forefinger is in line with the open pocket (Component 4, Step 3: Full wrist pronation), the chances are far greater that they will be able to execute a partial or full cradle (Component 5, Steps 2 and 3 ) than if they place the palm of their hand beside (Component 4, Step 2) or behind the stick (Component 4, Step 1).

\section{Component 5: Stick Head and Top Arm}

This component was the first one, and the only one, that appeared to meet the criterion for sign of the functions proposed by Roberton et al. (1980). They suggested that for a three-level sequence for a specific population, the younger children

would show a predominance of level 1, which would then decrease in frequency as the children grew older. As the decline in level 1 began, level 2 would start its rise. When level 3 appeared, level 2 would decline until it disappeared and level 3 had the greatest frequency of occurrence. (Roberton et al., 1980, p. 726)

Of the trials observed for the youngest children, 13\% were classified at Step 1 (stationary-little or no action), $87 \%$ at Step 2 (partial cradle), and none at Step 3 (full cradle). Of the trials observed for the oldest children, $8 \%$ were classified at Step $1,70 \%$ at Step 2, and 22\% at Step 3. For these older children, Step 1 has all but disappeared, Step 2 was predominant and Step 3 was becoming more accessible to more children (see Figure 4).

In both age groups, the least advanced pattern was not often observed, more so for the older of the two groups. For the 12-year-olds, although the majority of trials were categorized at Step 2, Step 3 was beginning to appear. Although we did not report data for Component 4 (top hand grip), the fact that $22 \%$ of the trials were classified at Step 3 for Component 5 was interpreted to indicate that the older children were able to use their top hand in such a way as to move the head of the stick through a full cradle (Boyd, 1969; Green \& Kurtz, 1989).

Two factors may have influenced results for Component 5. First, although both groups of children had had no playing experience with lacrosse, the older children came from Maryland, a state known for both men's and women's competitive lacrosse. Consequently, these children would have had the opportunity to see lacrosse being played on television or at spectator event. If these children had watched any men's games, in particular, they would have seen the cradling action brought about by the wrist of the top hand rolling back and forth (i.e., a combination of 

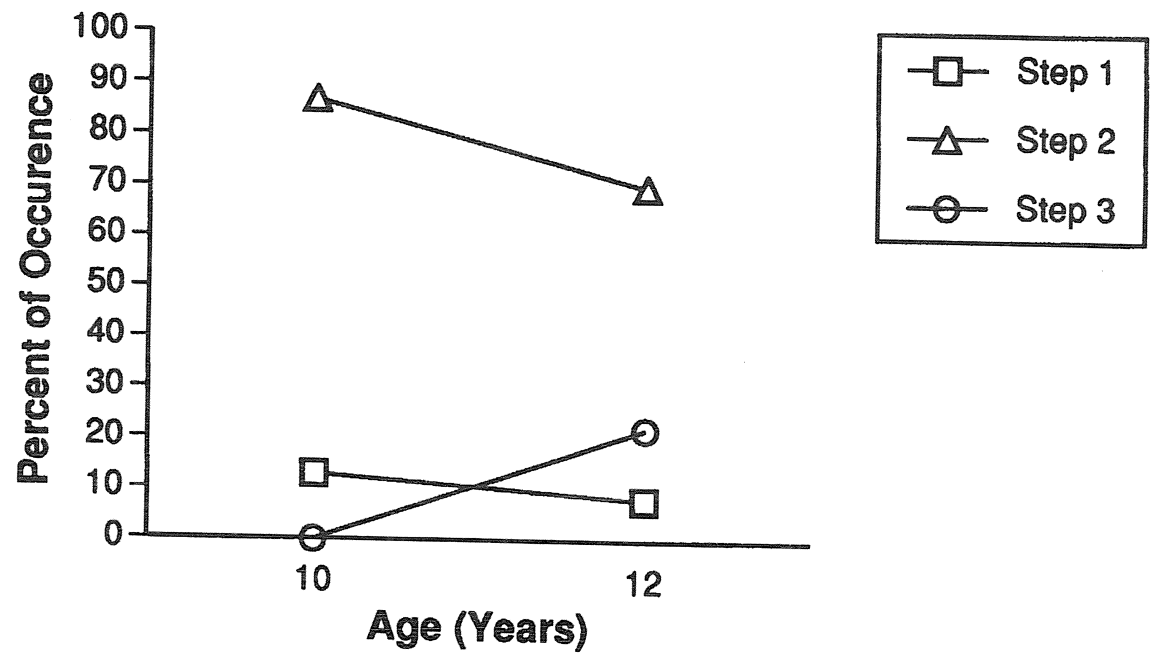

Figure 4-Stick head and top arm component percentages of occurrence.

pronation/supination and flexion/extension) as well as the fingers opening and closing on the stick to coincide with the running action (Hanna, 1980). These two actions are well-known techniques and are often used by adult players to help keep the ball in the stick, and thus produce a full cradle (Component 5, Step 3). Also, prior to the filming, some of the older children had observed one of the filming technicians throw and catch a lacrosse ball in which he clearly rolled his fingers and wrist when cradling. While waiting in line to take their turn, some of the children were observed trying to emulate this action. The younger children, on the other hand, came from Burlington, North Carolina, a city in which there is little opportunity to observe the adult form of lacrosse being played. Likewise, they did not see any player using the specialized cradling technique just described.

\section{Component 6: Position of Hands}

As with Components 1 and 2, the majority of all trials were categorized at the most advanced level (see Figure 5). For all trials observed, $97 \%$ were categorized at Step 4 and 3\% at Step 3 for the 10-year-olds. For the 12-year-olds, all trials were categorized at Step 4. This high frequency of occurrence at the most advanced level was attributed to the fact that the children were given time at the start of each trial to "get ready" before they ran the 54.86-m distance cradling. All seemed to know just where they wanted to put their hands, an action that suggested their teachers had carefully worked with them on this aspect of the cradle. Although most children held their sticks at least shoulder width apart, variations were noted.

No matter the length of the stick, the children's top hands were consistently placed close to the top of the stick. At times, however, their bottom hands were placed on the stick at a distance greater than shoulder width apart, but rarely at the extreme end of the stick. These variations, although representing what we hypothesized as the most advanced pattern, are important to recognize as they exert a 


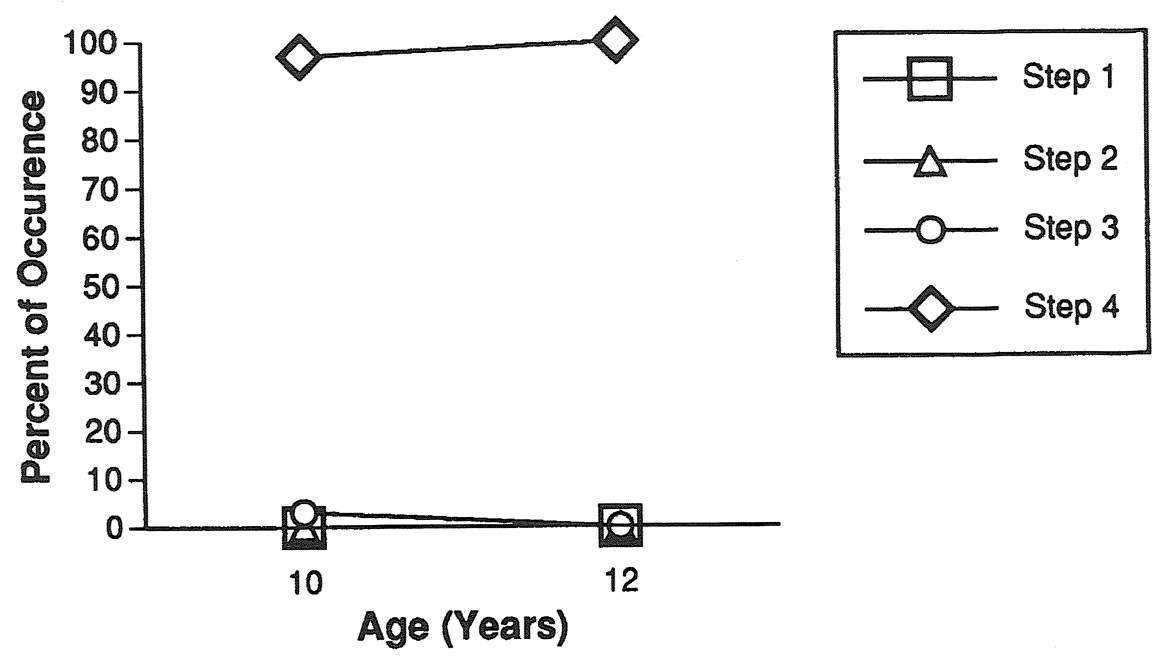

Figure 5 - Position of hands component percentages of occurrence.

strong influence on the observed developmental levels for Component 7 (bottom arm and hand).

\section{Component 7: Bottom Arm and Hand}

Data from this component (see Figure 6) revealed a number of problems. For both groups of children, most of the trials were classified as Step 1, 50\% for the 10-year-olds and $71 \%$ for the 12-year-olds. The occurrence of Step 2 for both groups was evident, although minimal: $13 \%$ for both. For the younger children, $29 \%$ of all trials were classified at Step 3, whereas only $15 \%$ were for older children. No children performed at the highest step (Step 4: elbow flexed, shoulder rotation). Unclassified trials represented attempts where children held their stick stationary in front of their body while they tried to cradle. Because of the unique way a lacrosse stick has to be held to perform the cradling action, it was understandable that none of the children were able to perform at the most advanced level or that the majority of occurrences were categorized at Step 1. What was not expected, however, was that (a) more of the older children would be categorized at Step 1 than the younger, (b) more trials would be categorized in Step 3 than in Step 2 for both groups, and (c) there would be twice as many occurrences for Step 3 for the 10-year-olds than for the 12-year-olds.

Two interpretations are suggested. One relates to the hypothesized order of the sequence and the other to the criterion selected to identify the groups on which the data were collected. Since fewer trials were categorized in Step 2 than in Step 1 , these steps may be incorrectly ordered. The original sequence was hypothesized on the assumption that moving the bottom arm in a flexed position of $90^{\circ}$ or less (i.e., at or above the waist) was more advanced than moving it below the waist while keeping it extended, partially flexed or some combination of the two. If, based on these data, we were to arrange the steps to reflect Roberton et al.'s (1980) criteria for developmental sequences, Steps 1 and 2 would be reversed. This rever- 

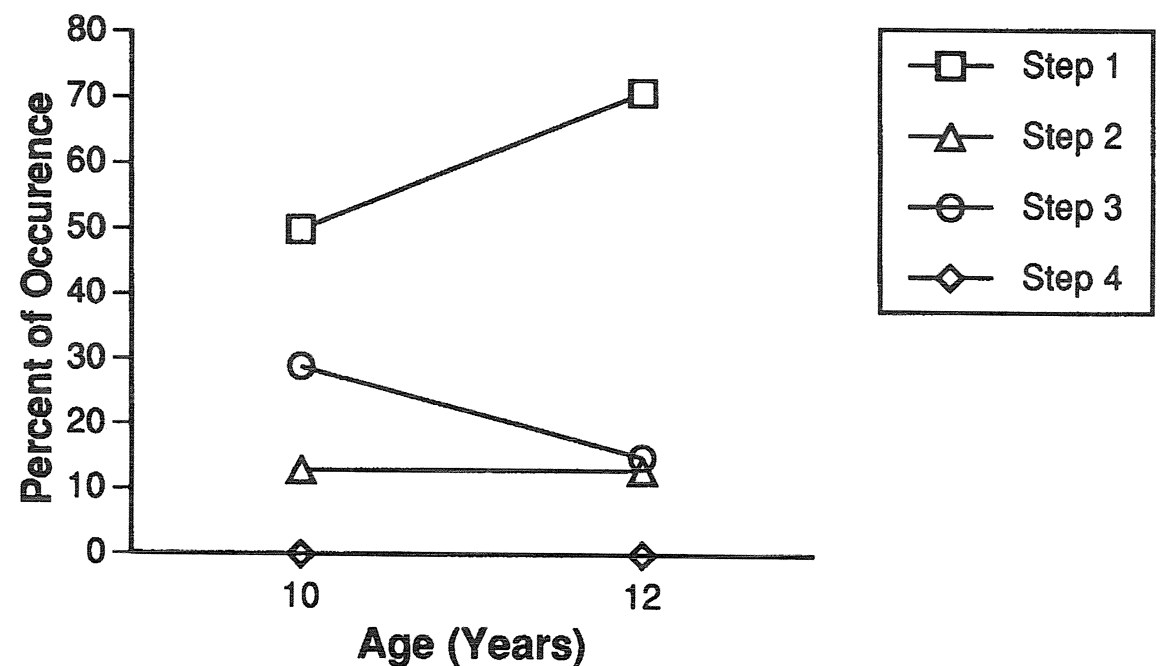

Figure 6-Bottom arm and hand action component percentages of occurrence. Eight and $1 \%$ of the trials could not be categorized for the 10 -year-old and 12 -year-old children, respectively.

sal suggests that it is easier to flex and extend the elbow when first learning to cradle than it is to keep it extended. Reversing these steps, however, does not indicate why more of the older children were performing at Step 1 than the younger children, and more of the younger children were performing at Step 3 than the older children-it should have been just the reverse.

Researchers who have proposed developmental sequences or applied the prelongitudinal screening technique as part of the validation process (Halverson $\&$ Williams, 1985; Strohmeyer et al., 1991) use age as the main criterion to identify their groups, particularly where fundamental motor skills were involved. When Messick (1991) applied the prelongitudinal screening technique to hypothesized developmental sequences for the overhead tennis serve, she used a combined set of criteria to include sex, age, experience, and ability to identify her groups (e.g., $57 \%$ were ranked at the state level). She characterized her participants as "experienced, competitive tennis players" (p. 250). As the data in this study illustrated, age may not be the best criterion to use for Component 7 , especially since the skill being studied was new to the children, and therefore, all participants were in the process of learning it.

\section{General Discussion and Implications}

This investigation represents one of the first attempts to hypothesize and validate developmental sequences for a skill related to a specific sport. As noted, Messick's (1991) partial validation of a tennis serve is the only similar investigation of a skill that is not considered a fundamental motor skill. Both studies were similar in that they focused on a sport skill rather than a fundamental skill. The two studies are different in that there were no basic movement patterns upon which to 
hypothesize sequences for the vertical cradle. In hypothesizing her sequences for the tennis serve, Messick (1991) drew from Roberton's $(1977,1978)$ work on developmental sequences for the forceful overarm throw and Langendorfer's (1987) study in which he compared Roberton's sequences with his hypothesized sequences for overhead striking. The lack of similar groundwork for lacrosse sequences may have contributed to the problems uncovered in this partial validation. Additionally, differences between the studies also suggest that we need to think about fundamental or basic skills as skills that occur within specific sport settings rather than only as foundational skills that cut across a number of skills (Wickstrom, 1983).

A lack of developmental variability was a problem for several of the hypothesized sequences. In these cases, we can question whether sequences were described at all. Components 1 and 2 are especially problematic in this regard. First, only two steps were hypothesized initially. In both components, more than $90 \%$ of trials were placed in the highest step. Developmental sequences are defined as a series of changes in a motor skill. A sequence of two changes meets this criterion only minimally. When one category of behavior (i.e., a developmental step) is only rarely seen, however, the argument for sequential change is weakened considerably. Additional study is necessary to clarify whether the sequences described in Components 1 and 2 represent change or simply an idiosyncrasy. The problem of developmental variability may be less of a problem for Component 1 than for Component 2. Despite the small number of trials placed at Step 1 for Component 1 , its status as a sequence is raised somewhat by the possibility that a new primitive level might be added. We will return to this point later.

Little developmental variability was observed for Component 6, despite four hypothesized levels. It is unclear why few, if any, participants were placed at the intermediate steps of the sequence. It may be that the hypothesized "changes" represent nothing more than individual patterns of variation and preference when incorporated into this skill. As described, the changes are quantitative differences in hand position. A different way to examine hand position would be in relation to body size (i.e., shoulder width) rather than as an absolute distance between the hands. Efficient positioning may be related to some body-scaled dimension, like shoulder width, rather than an absolute distance.

The issue of the relationship of body size to movement form is but one example of a performance constraint. The notion of constraints to performance was formally introduced to movement scientists by Newell in 1986. Constraints were defined as "features" (Newell, 1996, p. 347) that limited how an action could be performed. Newell discussed three types of constraints: organismic, environmental, and task. Organismic constraints were elements particular to the actor (i.e., the mover). They might be factors like strength, height, or level of motivation. Environmental constraints were external to the performer, and often difficult to modify or change. These features include weather, humidity, or playing surface. Task constraints could take several forms, including task goal, structure, rules, or equipment. The goal, structure, and rules of a game or sport can dictate a range of acceptable behaviors (i.e., movement patterns); the size or weight of a piece of equipment, like the lacrosse stick and ball used in this study, will impact how an action is performed.

Results of this investigation and the Strohmeyer et al. (1991) study demonstrated the importance of constraints in determining the way a task is performed. For example, in this study, equipment size was important to the children. When 
given the choice of selecting sticks of differing lengths, nearly one third (i.e., $31 \%$ or 16 of the 51 participants) chose a stick shorter than the one they typically used. This effect of equipment on the children's movement patterns was not studied directly in this investigation, but it is hard to imagine that it did not have some influence. None of the children had ever tried to cradle an adult or modified lacrosse stick before, and just holding a stick vertical in front of one's body can feel awkward. Further, Strohmeyer and colleagues (1991) found shifting task goals to be important since children used different patterns to catch depending on where a
ball was thrown.

Simply placing the stick in children's hands differently constrained (i.e., affected) the running pattern used by some children. Developmentally advanced running form includes use of an oppositional pattern between the arms and legs (Roberton \& Halverson, 1984). Although it was not observed in a large number of children, several participants "froze" their arm action while holding the stick in front of their body. "Freezing out" degrees of freedom, or limiting the action of specific body segments, is commonly observed in individuals learning new motor skills (Tuller, Turvey, \& Fitch, 1982, p. 251). Although additional study is necessary to determine whether this pattern is more widely observed in a broader sample of individuals, the Tuller et al. (1982) paper provides theoretical justification for inserting it as a new first, or least developmentally advanced step in Component 1 . Running with the stick disrupted the oppositional pattern of action for another $8 \%$ of the trials for children categorized at Step 1, nonopposition. For those children, however, their stick and arms moved in nonopposition to the running pattern (e.g., right arm and right leg moving forward together), often eliciting a jerky or seemingly disconnected series of movement patterns. Further study is necessary to confirm that these hypothesized changes in constraint represent developmental changes in movement. The children in this investigation were presumed to exhibit the most advanced, oppositional pattern when running without a stick. This task was not
directly tested, however.

The issue of the quality (i.e., effective use of pedagogical knowledge specific to a sport) or amount of instruction was not directly addressed as a constraint. The pattern of results reported for Component 3 (stick position), Component 5 (stick head and top arm), and Component 7 (bottom arm and hand) suggests this to be an important consideration. For Components 3 and 7 , results were the opposite of those hypothesized by the traditional age relationship. That is, younger children were categorized more often at higher developmental levels than their older peers. The more experienced teacher, both in terms of number of years of teaching experience and in lacrosse teaching background, worked with the younger children. Although the older children had more lacrosse lessons, the instructional time for the two groups was constant. The pattern of results was as hypothesized for Component 5 (stick head and top arm). As noted earlier, a filming technician inadvertently demonstrated the more advanced action, which some older children attempted to emulate. These results suggest that teachers' actions (e.g., feedback, demonstration, use of space, task design) throughout a lesson, are "critical constraints" in helping students to advance developmentally. It is clear that more systematic study of the relationship between teaching and the learning that subsequently occurs is
necessary to confirm this hypothesis.

Our results suggest two implications. First, in validating hypothesized sequences for skills specific to a sport, such as the vertical cradle in lacrosse, how 
groups are selected should be reconsidered. This study demonstrated that the traditional age relationship used to hypothesize sequences was not as helpful as when sequences for a fundamental motor skill were being validated. Messick (1991) recognized the importance of experience in tennis when she used age and experience/ability to identify her groups. Second, because the interaction is so tight between teaching and learning an unfamiliar skill, we probably should study beginners being taught over time by teachers with proven effectiveness in teaching the motor skill in question. We may get a more valid picture of how a skill such as the vertical cradle (i.e., a complex, unfamiliar skill) develops over time.

Little doubt exists in our minds of the need to identify developmental sequences for skills specific to a sport as they represent a unique way of understanding movement for teaching physical education (Shulman, 1986). Most importantly, they serve as tools for observation, assessment and interpretation about developmental progress. Understanding these sequences and how the steps within components, and the components themselves interrelate, gives us clues to how the structure and goal of an instructional task might be changed or how the equipment being used might need modification (Grossman, 1990; NASPE, 1995; Newell, 1986; Shulman, 1986). Developmental progress, that is, movement through the sequences, would occur only after a significant amount of practice had occurred as learners interacted with the teacher's skillful use of pedagogical content knowledge specific to the skill being learned (Barrett \& Collie, 1996). Student progress could be compared against Roberton et al.'s (1980) sign of the function criterion. In this case, age could be replaced by the length of the teaching unit. In addition, qualitative description of teacher actions in relation to specific student movement responses throughout the unit would inform us of pedagogical content knowledge specific to the context in question and suggest pedagogical content knowledge that potentially could be used by other teachers (Barrett \& Collie, 1996).

The results of this study suggest that it is time to think differently about the concept of sport-specific skills. Our results indicate there are skills specific to a sport that are not linked to a basic movement pattern. In other words, there are skills fundamental to the sport itself (e.g., the soccer or basketball dribble, the forearm pass in volleyball). The vertical cradle is a perfect example of this type of skill as it is considered to be basic and a part of all the skills of the game of lacrosse (Boyd, 1969; Green \& Kurtz, 19889; Hanna, 1980; Lewis, n.d.). It is these skills, then, that would need to be "used in particular ways" (Wickstrom, 1983, p. 9) to advance in a specific game or sport.

Additionally, we would be challenged to examine the relationship between the most advanced pattern of a motor skill fundamental to the sport and gamesplaying ability (Thorpe, Bunker, \& Almond, 1986). Knowledge of the cradle's basic movement pattern and how the different components develop over time, along with knowledge of what happens to the pattern when the skill is used in different contexts, becomes invaluable pedagogical content knowledge for teachers. For example, as mentioned earlier, when children first try to catch a ball they often bring up their bottom hand parallel with their top hand in an effort to keep the ball in the stick. What is significant about this example is that the action of trying to catch the ball (i.e., letting the ball come into the stick and then wrapping around it) is in effect one half of a cradle. When this situation occurs, teachers must use their "developmental knowledge" of the vertical cradle (i.e., developmental sequences) to help the children learn to catch because of the intimate relationship between the 
two skills. This same developmental knowledge of the cradle would also be used when trying to help children keep the ball in their stick following a successful interception or when a defense player is trying to mark them.

Thinking this way about skills specific to a sport encourages us to accept more readily the important role that knowledge of developmental sequences plays in teachers' pedagogical content knowledge and related actions. It seems strange that we have not acknowledged this void before. Perhaps it is because we have linked the notion of developmental sequences to fundamental motor skills so tightly (e.g., running, throwing, catching) and thus have failed to see the need for their application to sport skills and actual game play. What this study has shown us is that developmental sequences do exist for skills specific to a sport. We still have to discover, however, the best means to hypothesize and validate them consistent with their nature.

\section{References}

Barrett, K.R., \& Collie, S. (1996). Children learning lacrosse from teachers learning to teach it: The discovery of pedagogical content knowledge by observing children's movement. Research Quarterly for Exercise and Sport, 67, 297-309.

Boyd, M. (1969). Lacrosse playing and coaching (Revised ed.). London: Kaye \& Ward.

Broer, M.R. (1973). Efficiency of human movement (3rd ed.). Philadelphia: Saunders.

Glaser, B.B., \& Strauss, A.L. (1967). The discovery of grounded theory: Strategies for qualitative research. New York: Aldine.

Graham, G., Holt/Hale, S., \& Parker, M. (1993). Children moving (3rd ed.). Mountain View, CA: Mayfield.

Green, T.S., \& Kurtz, A.B. (1989). Modern women's lacrosse. Hanover, NH: ABK.

Grossman, P.L. (1990). The making of a teacher: Teacher knowledge and teacher education. New York: Teachers College.

Halverson, L.E., \& Williams, K. (1985). Developmental sequences for hopping over distance: A prelongitudinal screening. Research Quarterly for Exercise and Sport, 56, 37-44.

Hanna, M. (1980). Lacrosse for men and women. New York: Hawthorn/Dutton.

Hay, J.G. (1985). The biomechanics of sports techniques (3rd ed.). Englewood Cliffs, NJ: Prentice Hall.

Langendorfer, S. (1987). A prelongitudinal test of motor stage theory. Research Quarterly for Exercise and Sport, 58, 21-29.

Lewis, B.J. (n.d.). Play lacrosse the easy way. Surrey, England: Candidum Press.

Logsdon, B.J., Barrett, K.R., Ammons, M., Broer, M.R., Halverson, L.E., McGee, R., \& Roberton, M.A. (1977). Physical education for children: A focus on the teaching process. Philadelphia: Lea \& Febiger.

Messick, J.A. (1991). Prelongitudinal screening of hypothesized developmental sequences for the overhead tennis serve in experienced tennis players 9-19 years of age. Research Quarterly for Exercise and Sport, 62, 249-256..

National Association for Sport and Physical Education. (1995). Looking at physical education from a developmental perspective: A guide to teaching. Reston, VA: Author.

Newell, K.M. (1986). Constraints on the development of coordination. In M. Wade \& H.T.A. Whiting (Eds.), Motor development in children: Aspects of coordination and control (pp. 341-360). Dordrecht: Martinus Nijhoff.

Nichols, B. (1994). Moving and learning: The elementary school physical education experience (3rd ed.). St. Louis, MO: Mosby. 
Patton, M.Q. (1990). Qualitative evaluation and research methods (2nd ed.). Newbury Park, CA: Sage.

Roberton, M.A. (1977). Stability of stage categorizations across trials: Implications for the "stage theory" of overarm throw development. Journal of Human Movement Studies, 3, 49-59.

Roberton, M.A. (1978). Longitudinal evidence of developmental stages in the forceful overarm throw. Journal of Human Movement Studies, 4, 167-175.

Roberton, M.A. (1982). Describing "stages" within and across motor tasks. In J.A.S. Kelso \& J.E. Clark (Eds.), The development of movement control and co-ordination (pp. 293-307). New York: Wiley.

Roberton, M.A. (1989). Developmental sequence and developmental task analysis. In J.S. Skinner, C.B. Corbin, D.M. Landers, P.E. Martin, \& C.L. Wells (Ed.), Future directions in exercise and sport science research (pp. 369-381). Champaign, IL: Human Kinetics.

Roberton, M.A., \& Halverson, L.E. (1984). Developing children-Their changing movement. Philadelphia: Lea \& Febiger.

Roberton, M.A., Williams, K., \& Langendorfer, S. (1980). Pre-longitudinal screening of motor development sequences. Research Quarterly for Exercise and Sport, 51, 724-731.

Schmidt R.A. (1991). Motor learning \& performance: From principles to practice. Champaign, IL: Human Kinetics.

Schulman, L.S. (1986). Those who understand: Knowledge growth in teaching. Educational Researcher, 15(2), 4-14.

Seefeldt, V., \& Haubenstricker, J. (1982). Patterns, phases, or stages: An analytical model for the study of developmental movement. In J.A.S. Kelso \& J.E. Clark (Eds.), The development of movement control and coordination (pp. 309-318). New York: Wiley.

Strohmeyer, H.S., Williams, K., \& Schaub-George, D. (1991). Developmental sequences for catching a small ball: A prelongitudinal screening. Research Quarterly for Exercise and Sport, 62, 257-266.

Thorpe, R., Bunker, D., \& Almond, L. (1986). Rethinking games teaching. Loughborough, England: Loughborough University of Technology, Department of Physical Education and Sports Science.

Tuller, B., Turvey, M., \& Finch, H. (1982). The Bernstein perspective: II. The concept of muscle linkage or coordinative structure. In J.A.S. Kelso (Ed.), Human motor behavior: An introduction (pp. 253-270). Hillsdale, NJ: Erlbaum.

Wickstrom, R.L. (1983). Fundamental motor patterns (3rd ed.). Philadelphia: Lea \& Febiger.

Wild, M. (1938). The behavior pattern of throwing and some observations concerning its course of development in children. Research Quarterly, 9, 20-24.

Wild, M.R., \& White, D.E. (1924). Physical education for elementary schools. Cedar Falls: Iowa State Teachers College.

\section{Acknowledgment}

Funding for this research was provided from a grant from STX, Inc., Baltimore, Maryland, to the first author. 